\title{
Optimum design of Nd-doped fiber optical amplifiers
}

Rasmussen, Thomas; Bjarklev, Anders Overgaard; Lumholt, Ole; Øbro, Mads; Pedersen, Bo; Povlsen, Jørn Hedegaard; Rottwitt, Karsten

Published in:

I E E E Photonics Technology Letters

Link to article, DOI:

$10.1109 / 68.124873$

Publication date:

1992

Document Version

Publisher's PDF, also known as Version of record

Link back to DTU Orbit

Citation (APA):

Rasmussen, T., Bjarklev, A. O., Lumholt, O., Øbro, M., Pedersen, B., Povlsen, J. H., \& Rottwitt, K. (1992). Optimum design of Nd-doped fiber optical amplifiers. I E E E Photonics Technology Letters, 4(1), 49-51. https://doi.org/10.1109/68.124873

\section{General rights}

Copyright and moral rights for the publications made accessible in the public portal are retained by the authors and/or other copyright owners and it is a condition of accessing publications that users recognise and abide by the legal requirements associated with these rights.

- Users may download and print one copy of any publication from the public portal for the purpose of private study or research.

- You may not further distribute the material or use it for any profit-making activity or commercial gain

- You may freely distribute the URL identifying the publication in the public portal 


\section{CONCLUSION}

We have compared the power requirements for pumping erbium-doped fiber amplifiers at 800,980 , and $1480 \mathrm{~nm}$. The analysis used a quantitative amplifier model with measured emission and absorption cross-section spectra as inputs. It was shown that even under optimized conditions the pump power required to obtain similar amplifier performance is $7-8 \mathrm{~dB}$ higher when pumping in the $800-\mathrm{nm}$ band. For small-signal amplification the required pump power for 980 $\mathrm{nm}$ pumping is $2 \mathrm{~dB}$ lower than for $1480-\mathrm{nm}$ pumping. For a booster amplifier with a $1-\mathrm{mW}$ input signal, the minimum required pump power for $1480-\mathrm{nm}$ pumping is up to $1.7 \mathrm{~dB}$ lower than for $980-\mathrm{nm}$ pumping, although the drive current will be lower for the latter laser. When the specified noise figure is lower than $4 \mathrm{~dB}$ the pump wavelength for the $800-\mathrm{nm}$ band should be $806 \mathrm{~nm}( \pm 3 \mathrm{~nm})$ and the pumping scheme should be codirectional. A detailed experimental investigation of a $\mathrm{Ge} / \mathrm{Al} / \mathrm{P} / \mathrm{Er}$-silica fiber pumped in the 800 -nm band and at $980 \mathrm{~nm}$ showed that the pump power required to obtain similar small-signal gain for a $1551-\mathrm{nm}$ signal is $\sim 7 \mathrm{~dB}$ higher for the $800-\mathrm{nm}$ band, in good agreement with the model predictions.

\section{REFERENCES}

[1] R. I. Laming, M. C. Farries, P. R. Morkel, L. Reekie, D. N. Payne, P. L. Schrivener, F. Fontana, and A. Righetti, "Efficient pump wavelength of erbium-doped fibre optical amplifier," Electron. Lett., vol. 25 , pp. 12-14, 1989 .

[2] M. Horiguchi, M. Shimizu, M. Yamada, K. Yoshino, and H. Hanafusa, "Highly efficient optical fiber amplifier pumped by a $0.8 \mu \mathrm{m}$ band laser diode," Electron. Lett., vol. 26, pp. 1758-1759, 1990.

[3] Y. Kimura, K. Suzuki, and M. Nakazawa, "High gain erbium-doped fiber amplifier pumped in the $0.8 \mu \mathrm{m}$ pump band," in Proc. Eur. Conf. Opt. Commun., 1990, vol. 1, pp. 103-106.

[4] B. Pedersen, K. Dybdal, C. D. Hansen, A. Bjarklev, J. H. Povlsen, H. Vendeltorp-Pommer, and C. C. Larsen, "Detailed theoretical and experimental investigation of high-gain erbium doped fiber amplifier," IEEE Photon. Technol. Lett., vol. 2, pp. 863-865, 1990.

[5] B. Pedersen, A. Bjarklev, and J. H. Povlsen, "Design of erbium doped fibre amplifiers for $980 \mathrm{~nm}$ or $1480 \mathrm{~nm}$ pumping," Electron. Lett., vol. 27, pp. 255-257, 1991.

[6] S. Zemon, G. Lambert, W. J. Miniscalco, R. W. Davies, B. T. Hall, R. C. Folweiler, T. Wei, L. J. Andrews, and M. P. Singh, "Excited state cross sections for Er-doped glassess," in Proc. SPIE Symp. Fiber Laser Sources Ampl. \|, 1991, vol. 1373, pp. 21-32.

\title{
Optimum Design of Nd-Doped Fiber Optical Amplifiers
}

\author{
Thomas Rasmussen, Anders Bjarklev, Ole Lumholt, Mads $\emptyset$ bro, Bo Pedersen, J $\phi$ rn Hedegaard \\ Povlsen, and Karsten Rottwitt
}

\begin{abstract}
The waveguide parameters for a Nd-doped fluoride fiber amplifier have been optimized for small-signal and booster operation using an accurate numerical model. The optimum cutoff wavelength is shown to be $800 \mathrm{~nm}$ and the numerical aperture should be made as large as possible. Around $\mathbf{8 0 \%}$ booster quantum conversion efficiency can be reached for an input power of $10 \mathrm{dBm}$ and a pump power of $100 \mathrm{~mW}$ by the use of one filter.
\end{abstract}

\section{INTRODUCTION}

$\mathbf{M}$ OST of the optical communication systems installed operate at a signal wavelength of $1.3 \mu \mathrm{m}$. Thus, optical amplifiers for this wavelength are attractive components. The recent demonstration of gain around $1.3 \mu \mathrm{m}$ in a

Manuscript received June 18, 1991; revised October 15, 1991. This work was supported by the Danish Technical Research Council and the National Agency of Industry and Trade, Denmark. The cross-section spectrum was measured at British Telecom Research Laboratories and has been used with permission from M. Brierley.

The authors are with the Center for Broadband Telecommunications, Electromagnetics Institute, Technical University of Denmark, DK-2800 Lyngby, Denmark.

IEEE Log Number 9105115.
Nd-ZBLANP fiber [1] suggests a possible fiber amplifier, which will have the advantage over semiconductor amplifiers of being polarization independent and having very low insertion loss. So far the small-signal gain of the Nd-ZBLANP fiber amplifiers have been limited by saturation caused by a high level of amplified spontaneous emission (ASE) around $1050 \mathrm{~nm}$. However, significant improvement has been predicted [2] and demonstrated [3] by effectively filtering of the $1050 \mathrm{~nm}$ ASE. The objective of this letter is to improve the efficiency both for small-signal and large-signal operation by optimizing the waveguide geometry. The analysis, which is based on a full-scale numerical model, is performed both with and without a $1050 \mathrm{~nm}$ filter. Optimizations of Er-doped fiber amplifiers have shown that confinement of the active ions increases the gain [4]. Thus, we have included this in the analysis of the Nd-amplifier.

\section{MODEL}

The model used is based on a numerical solution of the rate equations for a four-level laser system, with inclusion of excited state absorption (ESA) at the signal wavelength, as described in [2]. Furthermore, the model is extended to 
include the spectra of the 900,1050 , and $1300 \mathrm{~nm}$ ASE. The Nd-doped fiber has a step-index profile, and the pump and signal wavelengths are 0.795 and $1.34 \mu \mathrm{m}$, respectively. The spontaneous emission lifetime is $0.72 \mathrm{~ms}$, the pump absorbtion cross section is $20.5 \cdot 10^{-25} \mathrm{~m}^{2}$, the ESA (at $1.34 \mu \mathrm{m}$ ) and signal cross sections are $0.35 \cdot 10^{-25} \mathrm{~m}^{2}$ and 5.15 . $10^{-25} \mathrm{~m}^{2}$, respectively, and the peak cross section value in the $1050 \mathrm{~nm}$ band is $27.2 \cdot 10^{-25} \mathrm{~m}^{2}$.

In [2] it was assumed that the $\mathrm{Nd}^{3+}$ ion, after excitation to a higher energy level by the ESA, decays instantaneously to the ground state. This worst-case assumption is investigated in [5] where it is proposed that a fraction of the ESA decays to the upper laser level. To investigate the influence of this on the fiber design we have done calculations for both ESA decay to the ground state and the upper laser level. These calculations have shown no more than $5 \%$ differences in gain. In the following the worst case assumption is adopted.

\section{Small-Signal Gain Optimization}

The optimum cutoff wavelength versus pump power $\left(P_{p}\right)$ is shown in Fig. 1 for two numerical apertures (NA's). The dashed curves refers to a situation where an optical filter has been inserted at the optimum distance from the input end [6], which is determined as the distance where $50 \%$ of the pump power is absorbed. This filter is assumed to absorb the 1050 $\mathrm{nm}$ ASE totally, and leave all other wavelength bands unaffected. The insets shows the small-signal gain versus cutoff wavelength $\left(\lambda_{c}\right)$ for $\mathrm{NA}=0.1$ and $\mathrm{NA}=0.4$. The figure indicates that one should choose NA as high as possible, and calculations for other numerical apertures confirm this. For small pump powers the cutoff wavelength should be chosen to $800 \mathrm{~nm}$, but for larger pump powers, the cutoff wavelength is a function of both NA and the pump power. To assure single-mode operation of the signal, $\lambda_{c}$ should be chosen less than or at $1300 \mathrm{~nm}$. The figure also shows that if a filter is inserted the optimum cutoff wavelength is lowered towards $800 \mathrm{~nm}$. A further analysis has shown that if the ASE at 1050 $\mathrm{nm}$ was totally removed throughout the fiber, the optimum cutoff wavelength would be $800 \mathrm{~nm}$ for all pump powers.

\section{Booster Optimization}

Fig. 2 shows the gain as a function of input signal power $\left(P_{s}\right)$ for two different designs [(a) NA $=0.4, \lambda_{c}=0.8 \mu \mathrm{m}$, (b) $\left.\mathrm{NA}=0.4, \lambda_{c}=1.3 \mu \mathrm{m}\right]$. The pump power is $100 \mathrm{~mW}$. In the small-signal region (the flat part of the curves) there is a significant difference between the two designs as discussed above, but in the booster-region (the decreasing part of the curves) no significant difference can be seen. This is also evident on the inset on Fig. 2, which shows the quantum conversion efficiency defined as $(G-1) P_{s} \lambda_{s} / P_{p} \lambda_{p}$, against $\lambda_{c}$ for NA $=0.1$ and NA $=0.4 . G$ is the gain and $\lambda_{s}$ and $\lambda_{p}$ the signal and pump wavelengths, respectively. There is a maximum around $800 \mathrm{~nm}$, but this is not significant. Notice that with one filter inserted one can reach a quantum conversion efficiency of nearly $80 \%$ with an input power of $10 \mathrm{dBm}$ and a pump power of $100 \mathrm{~mW}$.

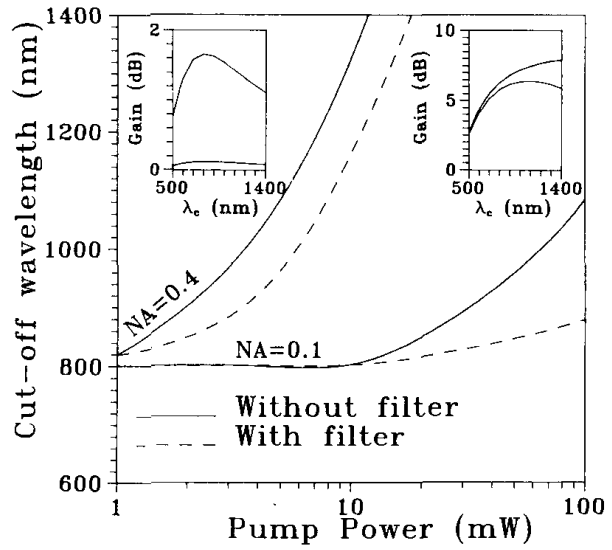

Fig. 1. Optimum cutoff wavelength versus pump power. The input signal power is $-40 \mathrm{dBm}$. The left insert shows gain versus cutoff wavelength for a pump power of $1 \mathrm{~mW}$, and the right for $100 \mathrm{~mW}$. The upper lines are for $\mathrm{NA}=0.4$ and the lower for $\mathrm{NA}=0.1$. No filter is used in the insets.

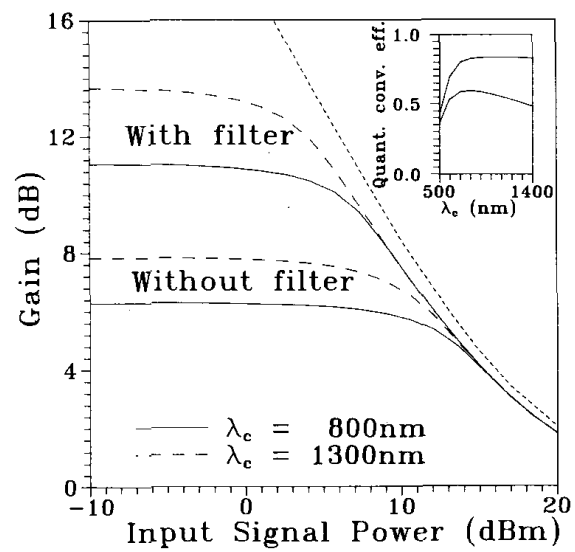

Fig. 2. Gain versus signal power for a pump power of $100 \mathrm{~mW}$. The dotted line to the right is the theoretical limit, when the quantum conversion efficiency is $100 \%$. The inset shows the quantum conversion efficiency versus cutoff wavelength.

\section{CONFINEMENT}

In order to investigate the influence which confinement of the Nd-doping has on small-signal gain and booster quantum conversion efficiency, we have calculated the curves shown in Fig. 3. A confinement of $50 \%$ improves the small-signal gain when the pump power is modest, but degrades the gain for larger pump powers. To explain this one has to consider the radial distributions of the involved intensities (all $\mathrm{LP}_{01}$ modes). Since the signal wavelength is $1300 \mathrm{~nm}$ and the dominant ASE wavelength is $1050 \mathrm{~nm}$, the signal has the broadest field distribution. Therefore, confining the active ions will be more favorable to the ASE, than the signal. When the pump power level is small, the ASE power is also small, and confinement increases the signal gain.

In a booster the ASE is negligible since the signal power is large. Thus, confining should increase the quantum conversion efficiency, which is also the case for small numerical 


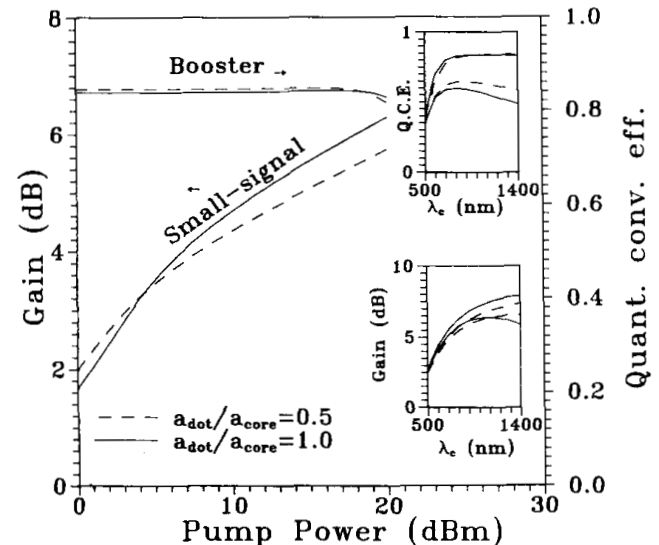

Fig. 3. Small-signal gain $\left(P_{s}=-40 \mathrm{dBm}\right)$ and booster quantum conversion efficiency $\left(P_{s}=15 \mathrm{dBm}\right)$ versus pump power with $100 \%$ and $50 \%$ confinement of the Nd-doping. NA $=0.4, \lambda_{c}=800 \mathrm{~nm}$. The upper inset shows booster quantum conversion efficiency versus $\lambda_{c}$, the lower inset shows small-signal gain versus $\lambda_{c}$, both for $100 \mathrm{~mW}$ of pump power, and $\mathrm{NA}=0.4$ and $\mathrm{NA}=0.1$.

apertures as seen on the upper inset on Fig. 3. However, for the fairly large NA of 0.4 , which is used in the main figure, the signal is well confined in the core so there is no significant improvement by confining the active ions in this case.

\section{Conclusion}

The waveguide parameters for a Nd-ZBLANP optical fiber amplifier has been optimized for the small signal and booster operation. In conclusion, the numerical aperture should always be chosen as high as possible, and the optimum cutoff wavelength should be chosen to $800 \mathrm{~nm}$ provided that the $1050 \mathrm{~nm}$ amplified spontaneous emission can be removed in the small-signal case. A booster quantum conversion efficiency of nearly $80 \%$ can be reached for an input power of $10 \mathrm{dBm}$ and pump power of $100 \mathrm{~mW}$ by the use of one filter.

By investigating two extreme cases of excited state absorption decay, we have shown that this does not influence the fiber design.

Finally, the Nd-dopant radius should be chosen equal to the core radius for the small-signal case. In the booster case there is an improvement in quantum conversion efficiency of 2.5 and $0.1 \%$ for numerical apertures of 0.1 and 0.4 , respectively, when the Nd-ion distribution is confined to $50 \%$ of the core radius.

\section{ACKNOWLEDGMENT}

The authors wish to thank Dr. E. Nicolaisen for fruitful discussions.

\section{REFERENCES}

[1] J. E. Pedersen, M. C. Brierly, S. F Carter, and P. W. France, "Amplification in $1300 \mathrm{~nm}$ telecommunications window in Nd-doped fluoride fiber," Electron. Lett., vol, 26, pp. 329-330, 1990.

[2] M. Øbro, B. Pedersen, A. Bjarklev, J. H. Povlsen, and J. E. Pedersen, "Highly improved fiber amplifier for operation around 1300 nm," Electron. Lett., vol. 27, no. 5, pp. 470-472, 1991.

[3] T. Sugawa, Y. Miyajima, and T. Komukai, "10 dB gain and high saturation power in a $\mathrm{Nd}^{3+}$-doped flourozirconate fibre amplifier,' Electron. Lett., vol. 26, no. 24, pp. 2042-2044, 1990.

[4] B. Pedersen, A. Bjarklev, O. Lumholt, and J. H. Povlsen, "Detailed design analysis of erbium doped fiber amplifiers," IEEE Photon. Technol. Lett., 1991.

[5] M. L. Dakss and W. J. Miniscalco, "Fundamental limits on $\mathrm{Nd}^{3+}$ doped fiber amplifier performance at $1.3 \mu \mathrm{m}$," IEEE Photon. Technol. Lett., vol. 2, pp. 650-652, Sept. 1990 .

[6] O. Lumholt, M. Øbro, A. Bjarklev, T. Rasmussen, B. Pedersen, J. E. Pedersen, J. H. Povlsen, and K. Rottwitt, "Optimum placement of filters in $1300 \mathrm{~nm}$ Nd-fiber amplifiers," Opt. Commun. to be published. 